\title{
Lean Construction Supply Chain: A Bibliometric Analysis of the Knowledge Base
}

\author{
Temidayo O., Osunsanmi ${ }^{1}$, Ayodeji E., Oke', and Clinton O., Aigbavboa1 \\ ${ }^{1}$ SARCHhI in Sustainable Construction Management and Leadership in the Built Environment, \\ Faculty of Engineering and the Built Environment. University of Johannesburg, South Africa. \\ *Corresponding author's e-mail:osunsanmidayo@gmail.com
}

\begin{abstract}
The construction industry known for its adoption of ideas from other industries has also adopted lean thinking from the manufacturing sector for managing construction supply chains. Towards the successful adoption of this concept, there is a need to establish the philosophy surrounding is application within the construction industry. Thus, this study conducts a bibliometric analysis with the intention of discovering intellectual progress within lean concepts, relevant authors and philosophies surrounding lean construction supply chain concepts. The study adopted VOSviewer software through the assistance of citation, co-citation and keywords analysis to present a bibliometric and network analysis. A total of eight hundred and fifty Scopus indexed articles were extracted and used for the analysis. Through the analysis we have revealed the most important authors, journals and articles supporting lean concept. Also discovered are the major school of thought related to lean construction supply chain which are; waste reduction, just in time, integration and pre-fabrication. This review points to the benefits of using bibliometric network analysis for unearthing the practices of lean construction supply chain. These findings contribute to using a new research methodology for analysing the contribution of lean concept to the construction supply chain.
\end{abstract}

\section{KEYWORDS}

Bibliometric analysis; Construction supply chain; Citation; Lean construction

\section{INTRODUCTION}

The construction industry is often known for the adoption of management techniques from the manufacturing industry. Bajjou and Chafi (2018) affirmed that among all the management technique lean is one of the most popular. Lean production was developed from the manufacture of Toyota cars designed by Engineer Ohno. According to Koskela et al. (2013), the term "lean" was developed by a research group conducting research on cars production to reflect the nature of waste reduction adopted by Toyota manufacturing in comparison with mass car production system. The comparison was made with Ford cars that made mass production system. But Ohno aimed at delivering cars to meet customer demand. The idea was to eliminate waste through shifting focus from the activity to the overall delivery system. Ohno perceived waste as the failure to meet the specific requirement of a customer with zero inventory (Koskela et al. 2013). It can be deduced 
that lean concepts aim at delivering value to the customer by eliminating waste that does not contributes to the customer value.

Ma et al. (2018) believed that the ability of lean concept to eliminate waste made it suitable for the construction industry as it is characterized by numerous waste on the construction site. Although Saurin (2017) stipulated that the construction industry has rejected multiple ideas from the manufacturing sector but lean fits into the agenda of the industry. For instance, delivering a project to meet the client's needs while eliminating waste and the unnecessary cost is the goal of every construction project manager. Also, Yunus et al. (2017) revealed that waste in manufacturing and construction also occurs from activity-centred thinking, therefore, an approach that encourages a change in thinking will be suitable for the construction industry. Consequently, it is reasonable to affirm that applying lean thinking will enhance the management of construction projects.

This study referred the application of lean thinking for managing construction project as lean construction supply chain. The management of construction supply (CSC) is complex when compared to other sectors due to the project-based nature of the construction industry (Jung 2017). Meng (2010) signified that the CSCM is complicated because it contains numerous dissimilar consultants. The consultant includes; designers, suppliers and many others who come together to work on a short-term basis for a project with this organisation having their supply chains. Mandeep et al. (2018) reported that the complexity in the construction supply chain could be seen in its structure as it contains a minimum of 3 tiers. The first tier is charged with the responsibility for preparing the project. While the second tier is responsible for the managerial activity during the project construction phase and the last tier is responsible for supplying the materials needed for the construction project. This implies that managing the construction supply chain can be broken down into numerous process.

Meng (2010) reported that managing construction process can either be driven by a pull or push system. In the push system, the construction project is planned, controlled and delivered without any regards to the customers' needs and wants with the assumptions that all construction projects (housing) will be disposed or sold on the market. However, as time changes coupled with high competition, the push system became outdated and it moved towards the pull system. This system is characterised by construction production triggered by the customers thereby requiring on-time delivery of construction project, integration of construction project team members and many others. The shift to the pull system in the construction industry leads to the adoption of lean thinking as a project management technique for meeting client needs at a reduced cost (Koskela et al. 2013).

The application of lean within the construction industry has attracted numerous research such as; (Ballard et al. 2007; Pereira and Cachadinha 2011; Wong and Ahmed 2018) but most of the research as focused on hinderance, benefits for implementing lean construction. However, there is a lack in research regarding the school of thought supporting lean construction supply chain. The understanding for the school of thought is significant because to implement lean thinking for CSC fully it requires the proper knowledge of the underlying concepts. Also, the school of taught or knowledge base will provide the opportunity for developing a framework for lean construction supply chain. 


\section{METHODS}

Saunders et al. (2009) opined that the aim of most review papers is targeted at evaluating existing literature concerning a field of study to determine the themes, school of thought, issues and suggest an area for further study. This opinion coincides with the aim of this study that focuses on unravelling the underlying school of thought supporting lean construction supply chain. There are different techniques for conducting a systematic review of literatures. They include systematic literature review, content analysis, meta-analysis and bibliometric analysis. This study adopted a combination of bibliometric and content analysis. van Eck and Waltman (2017) described bibliometric analysis as a statistical analysis of published articles and citations to reveal their impact within a specific field of study.

The articles analysed for this study were retrieved from Scopus database. The articles were extracted from the database using the following keywords "Lean thinking" "lean production" "lean construction" "lean supply chain" "construction supply chain management techniques" and "lean construction supply chain". Through using these keywords, an initial article of 12,583 was provided by Scopus after inputting "lean production" in the search bar. A review of the articles shows that the majority of them concentrates on lean within the manufacturing sector. To further refine the articles "lean construction" was inputted into the search within bar and it produced a total of 2,038 articles. However, since the aim of the research is focused on construction supply chain lean construction supply chain was inputted, and it produced a total of 850 articles. Therefore, a total of eight hundred and fifty Scopus indexed articles were extracted and used for the analysis.

The articles were analysed with VOS viewer software to provide the citation, co-citation, journals and author analysis. The citation and journal analysis assist in revealing the essential authors and journals that have contributed significantly to the development of lean construction supply chain. The important articles were further subjected to content analysis of literature review to reveal the school of thought guiding lean CSC. Whereas co-citation provides the understanding of the external impact of citations on a subject matter. van Eck and Waltman (2017) affirmed that cocitation analysis comes in various format author citation, journal citation and sources citation. This study adopted author co-citation because it believes that authors that are co-cited in a literature imply that they conduct literature in a similar research area.

\section{ANALYSIS OF ARTICLES}

The analysis of the articles extracted from the database is presented in this section. The analysis reveals the crucial authors, journals, articles and significant school of thought related to lean construction supply chain. Figure 1 presents the trend of publications related to lean construction supply chain. The chart shows that lean construction became a significant source of interest around 1991, but it only increases in 2005 to 35 articles within the Scopus database. Ever since there has been a rise in its yearly publication. It expanded drastically in 2016 and with some journals already publishing articles against 2019. This indicates that lean thinking as a system for managing construction supply chain is receiving attention among researchers with a probability for increasing in the coming years. 


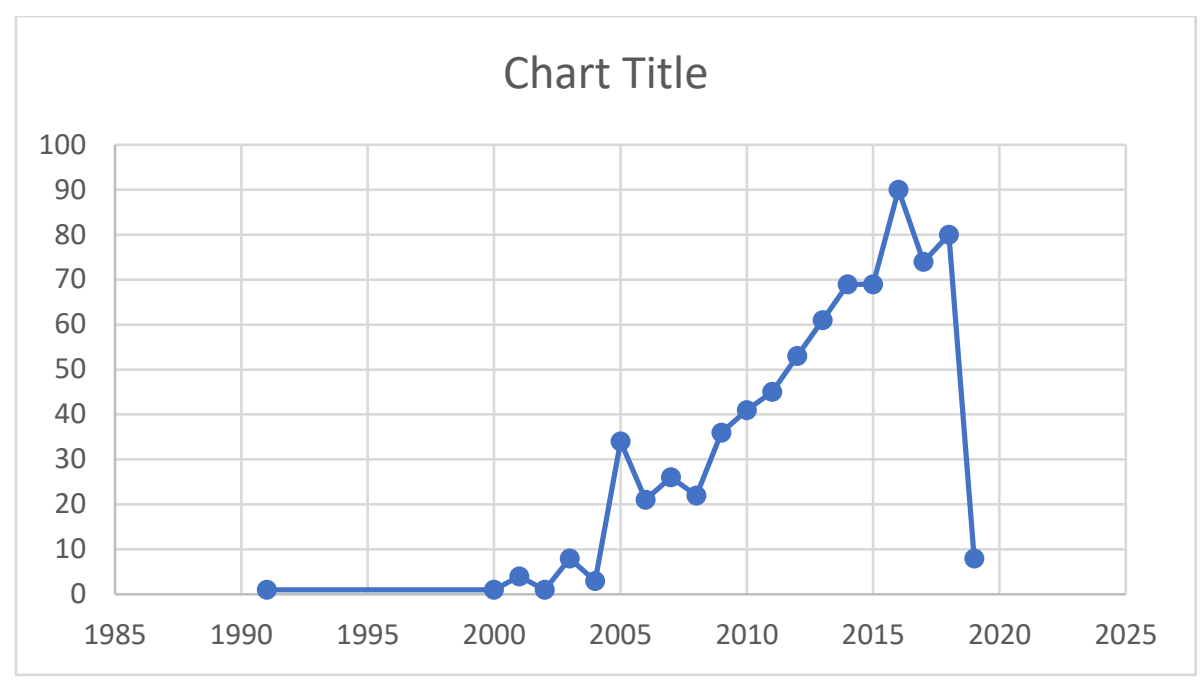

Figure 1. Trend in lean construction supply chain publications

\section{Leading journals for lean construction supply chain}

The top journals for lean construction supply chain are presented by Table 1. A look at the table shows that the journals are ranked according to their total link strength. The Vos viewer software produces the total strength link and it functions as a standard for weighing an attribute (van Eck and Waltman 2017). Also, the weight of an item also represents the level of importance given to such item. Therefore, the journal with the highest number of total strength link represents $=$ the most important journal concerning lean construction supply chain.

Table 1. Leading journals for lean construction supply chain

\begin{tabular}{lrrrr}
\hline & & & total link & Rank \\
Journals & Documents & citations & strength & \\
\hline Journal of construction engineering and management & 19 & 140 & 33 & 1 \\
Production planning and control & 14 & 72 & 28 & 2 \\
Construction management and economics & 12 & 91 & 25 & 3 \\
Engineering, construction and architectural & & & & 4 \\
management & 13 & 71 & 24 & \\
Journal of management in engineering & 7 & 173 & 24 & 5 \\
Construction innovation & 10 & 39 & 22 & 6 \\
International journal of production research & 10 & 305 & 19 & 7 \\
Automation in construction & 9 & 203 & 16 & 8 \\
Lean construction journal & 17 & 7 & 14 & 9 \\
Journal of cleaner production & 14 & 69 & 12 & 10 \\
Supply chain management & 5 & 58 & 12 & 11 \\
TQM journal & 7 & 23 & 11 & 12 \\
International journal of lean six sigma & 8 & 16 & 10 & 13 \\
Journal of engineering, design and technology & 6 & 316 & 9 & 14 \\
International journal of quality and reliability & & & & 15 \\
management & 7 & 150 & 7 & \\
\hline
\end{tabular}




\section{Source; VOS viewer software}

Table 1 shows that the top journals responsible for publishing lean construction supply chains are; the journal of construction engineering and management, production planning and control, construction management and economics, engineering construction and architectural management, Journal of management in engineering and construction innovation. This shows that sufficient articles related to lean construction supply chain can be found in the journals aforementioned.

\section{Influential authors}

Another strength of bibliometric analysis is the ability to identify prominent scholars within a field of study. Table 2 presents the list of prominent authors, and it shows the number of articles including the Scopus citations of each author. A cursory look at the table revealed that all the authors have a minimum of 5 articles that are index in Scopus with a minimum number of 0 citations in Scopus. The total link strength of the authors is presented in the third column which shows the overall strength of the authors within the lean construction supply chain. The total link strength represents the connectivity of the authors to other authors within the subject area, therefore, their level of influence was ranked based on that.

Table 2. Influential authors

\begin{tabular}{|c|c|c|c|c|}
\hline Author & $\begin{array}{l}\text { Scopus } \\
\text { articles }\end{array}$ & $\begin{array}{l}\text { Scopus } \\
\text { citations }\end{array}$ & Total link strength & Rank \\
\hline Koskela, 1. & 31 & 422 & 57 & 1 \\
\hline Tezel, A. & 13 & 36 & 49 & 2 \\
\hline Aziz z. & 7 & 19 & 26 & 3 \\
\hline Tzortzopoulos p. & 8 & 18 & 25 & 4 \\
\hline Saurin T.A. & 10 & 186 & 22 & 5 \\
\hline Matt, D.T. & 7 & 51 & 21 & 6 \\
\hline Rauch, E. & 7 & 38 & 21 & 7 \\
\hline Sacks, R. & 12 & 339 & 21 & 8 \\
\hline Dallasega, P. & 7 & 26 & 20 & 9 \\
\hline Pasquire, C. & 14 & 137 & 18 & 10 \\
\hline Ballard, G. & 20 & 347 & 17 & 11 \\
\hline Marodin, G.A. & 5 & 154 & 15 & 12 \\
\hline Tommelein, I.D. & 12 & 259 & 14 & 13 \\
\hline Al-hussein, M. & 10 & 152 & 10 & 14 \\
\hline Emuze, F. & 5 & 0 & 2 & 15 \\
\hline González, V. & 8 & 87 & 2 & 16 \\
\hline González, V.A. & 5 & 22 & 2 & 17 \\
\hline Bulhões, I.R. & 6 & 24 & 1 & 18 \\
\hline Lidelöw, H. & 5 & 7 & 0 & 19 \\
\hline Stehn, I. & 5 & 102 & 0 & 20 \\
\hline Formoso, C.T. & 11 & 63 & 10 & 21 \\
\hline
\end{tabular}

Table 2 shows that the topmost authors are Koskela with 31 Scopus document, 422 citations and a strength link of 43. Other influential authors are Tezel, Aziz, Tzortzopoulos, Saurin, Matt and 
Rauch. A further investigation into this authors reveals that they are from developed countries like Germany, United Kingdom, United States of America and Australia. Whereas authors with low total link strength like Emuze are from Africa, this represents the poor adoption of lean thinking within the Africa context.

\section{School of thoughts for lean construction supply chain}

This study adopts co-citation analysis to reveal the intellectual structure or school of thoughts underlying lean construction supply chain. This study adopted the author co-citation analysis that visualizes the similarities in the scholarship of authors. Zupic and Čater (2015) opined that coauthor citations analysis presents a network diagram showing the structure of knowledge base and different author's school of thoughts. Figure 2 presents the author co-citation analysis map calculated by VOSviewer software. The co-citation map shows the nodes that represent different authors. The size of the nodes depicts the number of co-citations of the author while the author with the biggest node indicates the number of times the author has been cited. A look at the map reveals that the authors are grouped into different coloured clusters that serves as the school of thoughts for each author. Figure 2 shows that the author is grouped into four colours namely; blue, green, yellow and red and it represents the school of thought surrounding lean construction supply chain.

In support of the co-author citation, a content analysis was conducted to review the articles published by the authors. The finding from the analysis reveals that the school of thought can be broken down into waste reduction, Just in time, Integration and prefabrication. The first school of thought depicted by colour green perceived that the major aim of lean construction supply chain is targeted at waste reduction. The leaders in this school of thought are (Ballard et al. 2007; Koskela et al. 2013; Koskela et al. 2007) depicted by the large nodes in figure 2. The authors in this category modelled waste in the construction according to Engineer Ohno of Toyota production. They revealed that waste in construction occurs due to the concentration on each activities of construction project alone. Whereas a majority of the waste is experienced at the construction stage due to inadequate information, poor design and weak integration of construction activities.

The second school of thought is depicted by the colour red, and it is dominated by authors such as (Liker 2004; Saurin 2017; Womack and Jones 1997). Authors in this school of thought recognise waste as the main core of lean construction supply chain but they believe that waste cannot be eliminated without the integration of construction activities. The third school of thought is depicted by colour yellow, and it is championed by (Dallasega and Rauch 2017; Dallasega et al. 2018; Matt 2014). According to this school of thought, engineering to order or prefabrication must be put in place to ensure effective lean construction of supply chain. The fourth school of thought is presented by colour blue from the review of articles published in this category believed that for effective lean construction Just in time techniques must be put in place. 
MOC SUMMIT / MAY 2019

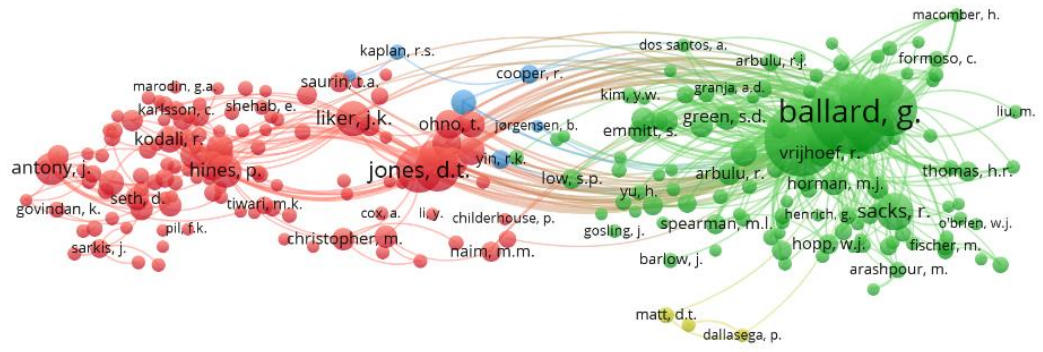

B vosviewer

Figure 2. Co-citation analysis

Source; VOSviewer

\section{CONCLUSION}

The construction industry is responsible for providing the infrastructures needed for the development of any country. Unfortunately, the construction project management techniques used for producing the infrastructures are characterised with numerous shortcomings causing project delays and wastage. These shortcomings made the industry adopted lean thinking for managing the construction supply chain. Lean thinking is a concept that has strived successfully in the manufacturing sector and is presently utilized within the construction industry.

Towards improving the practice of lean thinking for managing construction supply chain this study conducted a bibliometric analysis of its knowledge base within the construction industry. It concludes that lean thinking for managing construction supply chain is effectively adopted within the construction industry but is implementation in Africa is low judging from few research conducted in the study area. The primary school of thought supporting lean construction supply chain includes waste reduction, just in time, integration and pre-fabrication. The study recommends that a further research should be conducted on developing a framework based on the school of thought extracted from the analysis of the journals.

\section{ACKNOWLEDGEMENTS}

We acknowledge the department of construction management and quantity surveying University of Johannesburg South Africa.

\section{REFERENCES}

Bajjou, M. S., and Chafi, A. "Towards implementing lean construction in the Moroccan construction industry: Survey study." Proc., Proceedings of the 2018 International Conference on Optimization and Applications, ICOA 2018, 1-5.

Ballard, G., Tommelein, I., Koskela, L., and Howell, G. (2007). "Lean construction tools and techniques." Design and Construction, 227-255.

Dallasega, P., and Rauch, E. (2017). "Sustainable construction supply chains through synchronized production planning and control in engineer-to-order enterprises." Sustainability (Switzerland), 9(10). 
Dallasega, P., Rauch, E., and Frosolini, M. (2018). "A lean approach for real-time planning and monitoring in engineer-to-order construction projects." Buildings, 8(3).

Jung, M. "Agent-Based Simulation Framework for Supply Chain Management of Large-Scale Construction Projects." Proc., Congress on Computing in Civil Engineering, Proceedings, 289-296.

Koskela, L., Bølviken, T., and Rooke, J. "Which are the wastes of construction?" Proc., 21st Annual Conference of the International Group for Lean Construction 2013, IGLC 2013, 905-914.

Koskela, L., Howell, G., Ballard, G., and Tommelein, I. (2007). "The foundations of lean construction." Design and Construction, 211-226.

Liker, J. K. (2004). "The Toyota Way: 14 Management Principles from the World's Greatest Manufacturer McGraw-Hill Education."

Ma, X., Chan, A. P. C., Wu, H., Xiong, F., and Dong, N. (2018). "Achieving leanness with BIMbased integrated data management in a built environment project." Construction Innovation, 18(4), 469-487.

Mandeep, S., Mohammed, A., and J., K. D. (2018). "Critical factors for transferring and sharing tacit knowledge within lean and agile construction processes." Construction Innovation, 18(1), 64-89.

Matt, D. T. (2014). "Adaptation of the value stream mapping approach to the design of lean engineer-to-order production systems: A case study." Journal of Manufacturing Technology Management, 25(3), 334-350.

Meng, X. (2010). "Assessment framework for construction supply chain relationships: Development and evaluation." International Journal of Project Management, 28(7), 695707.

Pereira, D., and Cachadinha, N. "Lean construction in rehabilitation works - Suitability analysis and contribution for the definition of an application model." Proc., 19th Annual Conference of the International Group for Lean Construction 2011, IGLC 2011, 157-167.

Saunders, M., Lewis, P., and Thornhill, A. (2009). Research methods for business students, Pearson education.

Saurin, T. A. "Removing waste while preserving slack: The lean and complexity perspectives." Proc., IGLC 2017 - Proceedings of the 25th Annual Conference of the International Group for Lean Construction, 209-216.

van Eck, N. J., and Waltman, L. (2017). "Citation-based clustering of publications using CitNetExplorer and VOSviewer." Scientometrics, 111(2), 1053-1070.

Womack, J. P., and Jones, D. T. (1997). "Lean thinking-banish waste and create wealth in your corporation." Journal of the Operational Research Society, 48(11), 1148-1148.

Wong, L. S., and Ahmed, M. E. A. M. (2018). "A critical review of lean construction for cost reduction in complex projects." Jordan Journal of Civil Engineering, 12(4), 707-720.

Yunus, R., Noor, S. R. M., Abdullah, A. H., Nagapan, S., Hamid, A. R. A., Tajudin, S. A. A., and Jusof, S. R. M. "Critical Success Factors for Lean Thinking in the Application of Industrialised Building System (IBS)." Proc., IOP Conference Series: Materials Science and Engineering.

Zupic, I., and Čater, T. (2015). "Bibliometric methods in management and organization." Organizational Research Methods, 18(3), 429-472. 